\title{
Effects of different thermal insulation methods on the nasopharyngeal temperature in patients undergoing laparoscopic hysterectomy: a prospective randomized controlled trial
}

\author{
Guanyu Yang, Zefei Zhu, Hongyu Zheng, Shifeng He, Wanyue Zhang and Zhentao Sun ${ }^{*}$
}

\begin{abstract}
Background: This study explored the comparison of the thermal insulation effect of incubator to infusion thermometer in laparoscopic hysterectomy.

Methods: We assigned 75 patients enrolled in the study randomly to three groups: Group A: Used warming blanket; group B: Used warming blanket and infusion thermometer; group C: Used warming blanket and incubator. The nasopharyngeal temperature at different time points during the operation served as the primary outcome.

Results: The nasopharyngeal temperature of the infusion heating group was significantly higher than that of the incubator group $60 \mathrm{~min}$ from the beginning of surgery (T3): $36.10 \pm 0.20$ vs $35.81 \pm 0.20(P<0.001) 90$ min from the beginning of surgery (T4): $36.35 \pm 0.20$ vs $35.85 \pm 0.17(P<0.001)$. Besides, the nasopharyngeal temperature of the incubator group was significantly higher compared to that of the control group $60 \mathrm{~min}$ from the beginning of surgery (T3): $35.81 \pm 0.20$ vs $35.62 \pm 0.18$ ( $P<0.001$ ); $90 \mathrm{~min}$ from the beginning of surgery (T4): $35.85 \pm 0.17$ vs $35.60 \pm 0.17(P<0.001)$. Regarding the wake-up time, that of the control group was significantly higher compared to the infusion heating group: $24 \pm 4$ vs $21 \pm 4(P=0.004)$ and the incubator group: $24 \pm 4$ vs $22 \pm 4(P=0.035)$.

Conclusion: Warming blanket $\left(38^{\circ} \mathrm{C}\right)$ combined infusion thermometer $\left(37^{\circ} \mathrm{C}\right)$ provides better perioperative thermal insulation. Hospitals without an infusion thermometer can opt for an incubator as a substitute.
\end{abstract}

Trial registration: This trial was registered with ChiCTR2000039162, 20 October 2020.

Keywords: Laparoscopic, Infusion thermometer, Warming blanket, Incubator, Nasopharyngeal temperature

\footnotetext{
*Correspondence: gentlesun@126.com

Department of Anesthesiology, Pain and Perioperative Medicine, The First Affiliated Hospital of Zhengzhou University, Zhengzhou, Henan Province, China
}

C C The Author(s). 2021 Open Access This article is licensed under a Creative Commons Attribution 4.0 International License, which permits use, sharing, adaptation, distribution and reproduction in any medium or format, as long as you give appropriate credit to the original author(s) and the source, provide a link to the Creative Commons licence, and indicate if changes were made. The images or other third party material in this article are included in the article's Creative Commons licence, unless indicated otherwise in a credit line to the material. If material is not included in the article's Creative Commons licence and your intended use is not permitted by statutory regulation or exceeds the permitted use, you will need to obtain permission directly from the copyright holder. To view a copy of this licence, visit http://creativecommons.org/licenses/by/4.0/ The Creative Commons Public Domain Dedication waiver (http://creativecommons.org/publicdomain/zero/1.0/) applies to the data made available in this article, unless otherwise stated in a credit line to the data. 


\section{Background}

Reports describe perioperative hypothermia as a condition whereby the core body temperature drops below $36{ }^{\circ} \mathrm{C}$ [1]. Its incidence rate ranges between 25 and $90 \%$ [2]. Of note, perioperative hypothermia is associated with a range of complications, such as intraoperative coagulation dysfunction, delayed postoperative recovery, incision infection, among others [3, 4].

Laparoscopic surgery presents benefits, including less trauma, less bleeding, more rapid postoperative recovery, fewer surgical complications, etc. [5, 6]. Compared to open surgeries, the abdominal cavity is relatively more closed, however, anesthetic factors, persistent $\mathrm{CO}_{2}$ pneumoperitoneum during surgery, and the utilization of huge amounts of irrigating fluid may induce hypothermia $[7,8]$.

In this study, our main focus was to compare the effects of two different thermal insulation methods in laparoscopic hysterectomy.

\section{Methods}

Approval for this prospective, single-blind, randomized, controlled study was issued by the Ethics Committee of the First Affiliated Hospital of Zhengzhou University (2020-KY-176), registered at http://www.chictr.org.cn/ index.aspx (ChiCTR2000039162) on 20 October 2020. All patients signed informed consent. The protocol for this work strictly conformed with the international guidelines for randomized clinical studies and the CONSORT Guidelines.

We scheduled 75 patients for elective laparoscopic hysterectomy. Inclusion criteria included:1) Patients aged 40-65 years; 2) patients classified in the American Society of Anesthesiologists' physical status class of I to II; 3) patients without severe heart, liver, kidney disease;
4) patients with no history of severe respiratory or cerebrovascular disease. Exclusion criteria included: 1) preoperative anemia; 2) intraoperative blood transfusion; 3) transition to open surgery. Using a random number table, we randomly divided the 75 patients into 3 groups: The Control group (A), infusion heating group (B), and incubator group $(C)$.

\section{Study protocol}

Premedication was not given to any patient. The operating room was maintained at $22-24{ }^{\circ} \mathrm{C}$. All three groups were provided with warming blankets, which they turned on an hour in advance to achieve the preset temperature $\left(38^{\circ} \mathrm{C}\right)$. Upon entry to the operating room, we first administered the patients in the three groups with an injection of $500 \mathrm{ml}$ Ringer's lactate solution and followed by $500 \mathrm{ml}$ succinylated gelatin. The infusion speed was maintained at $10 \mathrm{ml} / \mathrm{min}$. Notably, in cases where the above liquids were both infused and replaced with 100 $\mathrm{ml}$ Ringer's lactate solution, we ensured that the infusion path was clear and the infusion speed was nearly stopped. In group A, the infusion fluid was not treated and maintained at room temperature; in group B, we heated the infusion fluid by the infusion thermometer, and set the target temperature of the infusion thermometer $37^{\circ} \mathrm{C}$; in group $\mathrm{C}$, the infusion fluid was incubated with the set target temperature at $37^{\circ} \mathrm{C}$.

ECG, BP, HR, $\mathrm{SpO}_{2}$, and BIS were monitored in all patients after they got into the operating room. Sufentanil $0.5 \mu \mathrm{g} / \mathrm{kg}$, cisatracurium $0.25 \mathrm{mg} / \mathrm{kg}$ and etomidate $0.2 \mathrm{mg} / \mathrm{kg}$ were intravenously administered as anesthetic induction. Following the insertion of the laryngeal mask, the ventilator was set at $\mathrm{V}_{\mathrm{T}} 6 \sim 8 \mathrm{ml}$ $/ \mathrm{kg}, \mathrm{FiO}_{2} 50 \%$, I: E 1: 2, RR12 20 times $/$ min. $\mathrm{P}_{\mathrm{ET}} \mathrm{CO}_{2}$ was maintained at $35 \sim 45 \mathrm{mmHg}$. Anesthesia was

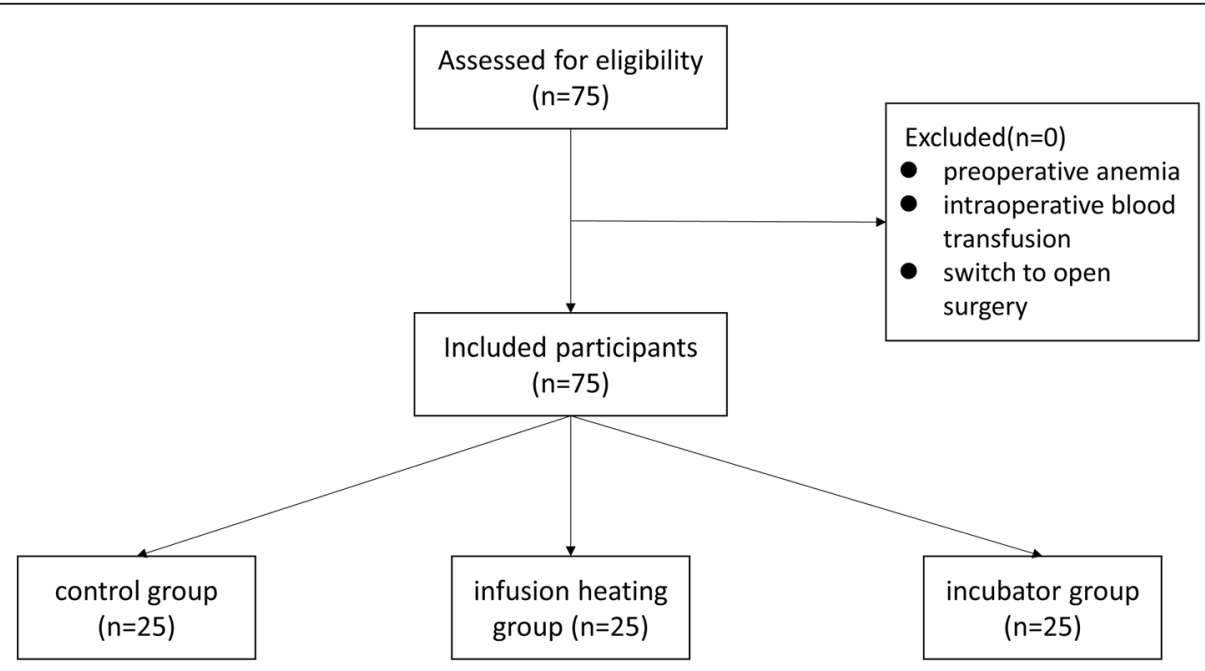

Fig. 1 Participant flowchart 
maintained with sevoflurane (gas flow at $2 \mathrm{~L} / \mathrm{min}$ ), remifentanil, and cisatracurium. Sevoflurane was titrated to maintain BIS of 40 to 60 during surgery.

The nasopharyngeal temperature was assessed following the induction of anesthesia in the three groups. Briefly, the nasopharyngeal probe was inserted to of about $1 \mathrm{~cm}$ depth beyond the first scale $(10 \mathrm{~cm})$. It was then secured with tape to maintain the depth. Vital signs were stabilized during the operation. At lower intraoperative nasopharyngeal temperature below $35^{\circ} \mathrm{C}$, the temperature of the warming blanket was raised to maintain the patient's nasopharyngeal temperature above $35^{\circ} \mathrm{C}$.

\section{Outcome measurements}

In the three groups, the primary outcome was the nasopharyngeal temperature at $5 \mathrm{~min}$ post anesthesia induction (T1), $30 \mathrm{~min}$ (T2), $60 \mathrm{~min}$ (T3), and $90 \mathrm{~min}$ (T4) at the beginning of surgery, whereas the secondary outcome was wake-up time.

\section{Statistical analyses}

SPSS (version 22.0, SPSS Inc., Chicago, IL, USA) was applied to analyze all statistical data. Measurement data were expressed as mean \pm standard deviation. We adopted a one-way analysis of variance for comparison between groups; the nasopharyngeal temperature was compared at different time points via repeated measurement ANOVA. For counting data, the Chi-square test was used for comparison. $P<0.05$ denoted statistical significance.

The sample size was established using GPower (version 3.1.9.2, Franz Faul, Universitat Kiel, Germany). Reports have demonstrated that a core temperature difference of $0.5^{\circ} \mathrm{C}$ is clinically significant; it is the smallest difference associated with hypothermic complications [9]. With the significance level $(\alpha)$ set at 0.05 , and power(1- $\beta$ ) at 0.9 , each group should include 22 patients, assuming that the withdrawal rate is $10 \%$. Eventually, each group comprises 25 patients.

\section{Results}

Of the 75 enrolled patients (Fig. 1), none exhibited intraoperative nasopharyngeal temperature below $35^{\circ} \mathrm{C}$.

\section{Primary outcome}

Compared to the incubator group, the nasopharyngeal temperature of the infusion heating group was significantly higher at $60 \mathrm{~min}$ from the beginning of surgery (T3): $36.10 \pm 0.20$ vs $35.81 \pm 0.20(P<0.001)$; $90 \mathrm{~min}$ from the beginning of surgery (T4): $36.35 \pm 0.20$ vs $35.85 \pm$ $0.17(P<0.001)$. Besides, the nasopharyngeal temperature of the incubator group was significantly higher than that of the control group $60 \mathrm{~min}$ from the beginning of surgery (T3): $35.81 \pm 0.20$ vs $35.62 \pm 0.18(P<0.001)$; $90 \mathrm{~min}$
Table 1 Nasopharyngeal temperature at different points in three groups

\begin{tabular}{llllll}
\hline Group & $\mathbf{n}$ & T1 & T2 & T3 & T4 \\
\hline A & 25 & $36.40 \pm 0.19$ & $35.88 \pm 0.21^{\mathrm{t}}$ & $35.62 \pm 0.18^{\mathrm{t}}$ & $35.60 \pm 0.17^{\mathrm{t}}$ \\
B & 25 & $36.37 \pm 0.24$ & $35.92 \pm 0.24^{\mathrm{t}}$ & $36.10 \pm 0.20^{* \mathrm{t}}$ & $36.35 \pm 0.20^{*}$ \\
C & 25 & $36.35 \pm 0.21$ & $35.88 \pm 0.18^{\mathrm{t}}$ & $35.81 \pm 0.20^{* \# \mathrm{t}}$ & $35.85 \pm 0.17^{* \text { \#t }}$ \\
\hline
\end{tabular}

Values are presented as mean \pm standard deviation

$5 \mathrm{~min}$ after anesthesia induction (T1), $30 \mathrm{~min}$ at the beginning of surgery (T2), $60 \mathrm{~min}$ at the beginning of surgery (T3), $90 \mathrm{~min}$ at the beginning of surgery (T4)

${ }^{*} P<0.05$ compared to the same time of Group A

${ }^{\#} P<0.05$ compared to the same time of Group $B$

${ }^{\mathrm{t}} P<0.05$ compared to $\mathrm{T} 1$

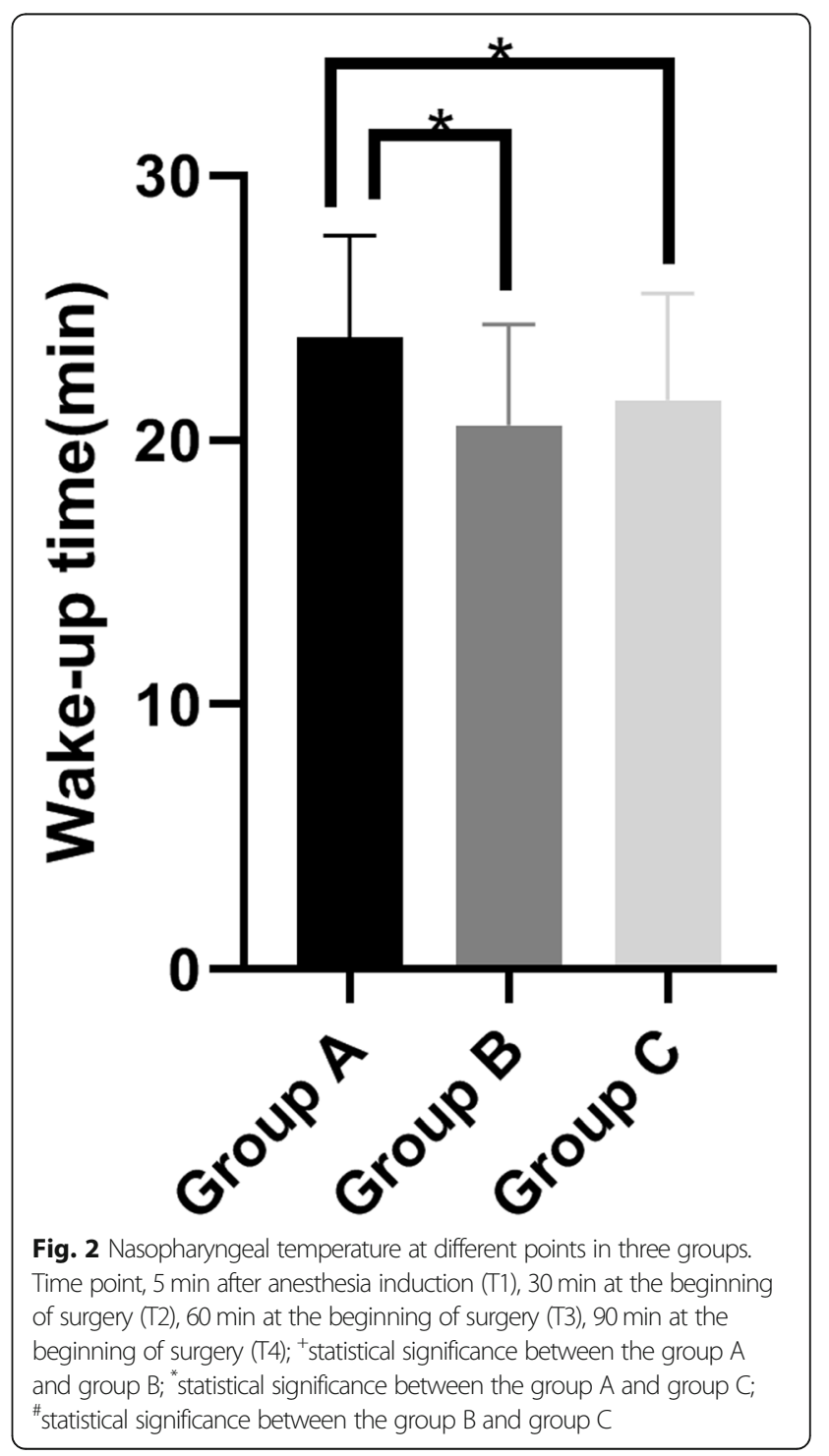


Table 2 Descriptive variables of the group A, group B and group C

\begin{tabular}{|c|c|c|c|c|c|}
\hline & Group $A(n=25)$ & Group $B(n=25)$ & Group $C(n=25)$ & $F$ value & $P$ value \\
\hline Age (years) & $53.28 \pm 6.91$ & $51.52 \pm 7.6$ & $54.32 \pm 6.30$ & 1.034 & 0.361 \\
\hline BMI $\left(\mathrm{kg} / \mathrm{m}^{2}\right)$ & $23.31 \pm 3.07$ & $23.50 \pm 2.91$ & $23.62 \pm 3.01$ & 0.066 & 0.936 \\
\hline ASA grade(I/II) & $13 / 12$ & $16 / 9$ & $12 / 13$ & / & 0.497 \\
\hline Surgery time (min) & $108 \pm 8$ & $111 \pm 8$ & $109 \pm 9$ & 0.770 & 0.467 \\
\hline Anesthesia time (min) & $135 \pm 9$ & $139 \pm 8$ & $136 \pm 9$ & 1.279 & 0.284 \\
\hline Blood loss (ml) & $38.60 \pm 6.70$ & $39.80 \pm 6.69$ & $40.28 \pm 8.84$ & 0.335 & 0.717 \\
\hline Urine output (ml) & $338.00 \pm 96.05$ & $340.00 \pm 76.38$ & $358.00 \pm 89.77$ & 0.394 & 0.676 \\
\hline Wake-up time $(\min )^{a}$ & $24 \pm 4$ & $21 \pm 4$ & $22 \pm 4$ & 4.816 & 0.011 \\
\hline Infusion volume (ml) & 1000 & 1000 & 1000 & / & / \\
\hline
\end{tabular}

Values are presented as mean (standard deviation) or counts

ASA American society of anesthesiologists, BMI Body Mass Index

a Wake-up time: The time from the patient stops inhaling sevoflurane until the laryngeal mask was removed

from the beginning of surgery (T4): $35.85 \pm 0.17$ vs $35.60 \pm 0.17(P<0.001)$ (Table 1)(Fig. 2).

\section{Secondary outcomes}

The wake-up time of the control group was significantly higher than that of the infusion heating group: $24 \pm 4$ vs $21 \pm 4(P=0.004)$ and the incubator group: $24 \pm 4$ vs $22 \pm 4(P=0.035)$ (Table 2) (Fig. 3).

\section{Discussion}

The present findings demonstrated that nasopharyngeal temperature decreased significantly in the three groups from $\mathrm{T} 1$ to $\mathrm{T} 2$. We revealed that general anesthesia induces peripheral vasodilation, which impedes the function of blood vessels to regulate the body temperature via contraction. Meanwhile, general anesthesia inhibits central thermoregulation of the body, whereas anesthetic drugs lower the metabolic rate $[10,11]$. At relatively low operating room temperature, a lot of heat is absorbed by preoperative disinfection and intraoperative infusion;

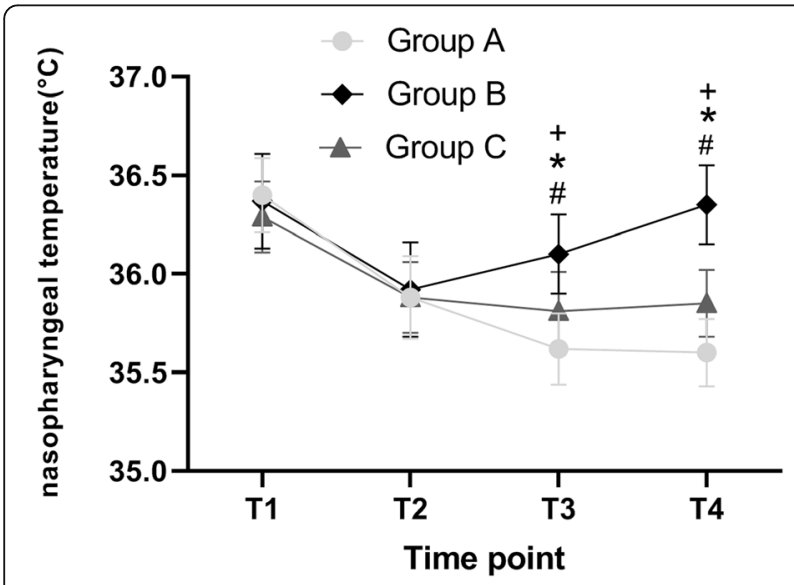

Fig. 3 Wake-up time in three groups; ${ }^{*} P<0.05$ some heat is propelled by continuous $\mathrm{CO}_{2}$ infusion during the operation $[8,12]$.

Herein, the nasopharyngeal temperature of the T2 to the T3 control group and the incubator group continuously decreased. Notably, the degree of decrease in the incubator group was less compared to that of the control group. The rise in the nasopharyngeal temperature of the infusion heating group demonstrated that the use of a warming blanket alone $\left(38^{\circ} \mathrm{C}\right)$ was inefficient to maintain the patient's body temperature. Maybe it needed a higher temperature. Furthermore, the infusion fluid in the incubator group was not continuously heated. In consequence, the temperature gradually decreased over time. It is solely in the infusion heating group whereby the rise in the patient's body temperature was induced by a warming blanket and infusion thermometer.

As the nasopharyngeal temperature of the T3 to T4 control group started to stabilize, the nasopharyngeal temperature of the incubator group began to rise, though lower than T1. The nasopharyngeal temperature of the infusion heating group continuously rose, with no significant difference from $\mathrm{T} 1$. We deduced that the temperature of the patients was potentially maintained at the preoperative level when the warming blanket $\left(38^{\circ} \mathrm{C}\right)$ combined infusion thermometer $\left(37^{\circ} \mathrm{C}\right)$ was used for $90 \mathrm{~min}$.

Moreover, the wake-up time of the control group was significantly higher compared to that of the infusion heating group and the incubator group. This was primarily attributed to the low-temperature status, which lowered the uptake capacity of the liver for drugs and the kidney capacity to excrete drugs. Consequently, there arises an impact on the metabolism of anesthetic drugs in the body which is potentially associated with prolonged wake-up time [13, 14].

As one of the vital signs, body temperature has increasingly been attractive in the perioperative period in recent years. However, the maintenance of body 
temperature during the perioperative period is unsatisfactory. Of note, this may be linked to the insufficient attention paid by medical staff to maintain body temperature. Besides, there is no protective device for body temperature in hospitals, for example, an infusion thermometer $[15,16]$. Usually, the incubator is an essential equipment for hospitals to preserve the irrigating fluid used during the operation. The present study fully utilized the equipment to preserve the injected fluid during the operation. This aimed to achieve the effect of fluid heating. Although the patient experienced hypothermia during the operation, the temperature drop was minimal. Also, the wake-up time was short. We, therefore, recommend this method for hospitals without a better insulation device, owing to its straightforward use, low cost and we expect this method to be popularized in clinical practice.

This work is limited to the observation time which was restricted to $90 \mathrm{~min}$. Thus, for a longer duration of surgery, it remains unclear whether the temperature of the warming blanket and infusion thermometer should be adjusted, which warrants further exploration.

\section{Conclusions}

Warming blanket $\left(38^{\circ} \mathrm{C}\right)$ combined infusion thermometer $\left(37^{\circ} \mathrm{C}\right)$ provides better perioperative thermal insulation. Notably, hospitals without an infusion thermometer may still opt for an incubator as a substitute.

\section{Abbreviations}

BMI: Body Mass Index; ASA: American Society of Anesthesiologists; ECG: Electrocardiogram; BP: Blood Pressure; HR: Heart Rate; $\mathrm{SpO}_{2}$ : Pulse Oxygen Saturation; BIS: Bispectral Index

\section{Acknowledgements}

This research was supported by the department of gynaecology of the First Affiliated Hospital of Zhengzhou University.

\section{Authors' contributions}

Study design: GY, ZZ, ZS. Study conduct: GY, HZ, SH. Data analysis: GY, ZZ, WZ, ZS. Writing paper: GY, ZZ, HZ, SH, WZ, ZS. All authors read and approved the final manuscript version.

\section{Funding}

This study was supported by the Henan Provincial Science and Technology Research Project (2018010006).

\section{Availability of data and materials}

The raw data of this study are available from the corresponding author on reasonable request.

\section{Declarations}

\section{Ethics approval and consent to participate}

This study was approved by the Ethics Committee of the First Affiliated Hospital of Zhengzhou University on May 31, 2020(2020-KY-176). All patients signed the informed consent.

\section{Consent for publication}

Not applicable.

\section{Competing interests}

None.

Received: 23 November 2020 Accepted: 26 March 2021

Published online: 05 April 2021

\section{References}

1. John M, Crook D, Dasari K, Eljelani F, El-Haboby A, Harper CM. Comparison of resistive heating and forced-air warming to prevent inadvertent perioperative hypothermia. Br J Anaesth. 2016;116(2):249-54. https://doi. org/10.1093/bja/aev412

2. Alexander $T$, Anselm B, Jan H, Berthold B, Hinnerk W, Ernst-Peter $H$. Preventing inadvertent perioperative hypothermia. Dtsch Arztebl Int. 2015; 112:166-72

3. Suman R, Edward M, Jie N, Sessler Daniel I. The effects of mild perioperative hypothermia on blood loss and transfusion requirement. Anesthesiology. 2008;108:71-7.

4. Melling AC, Ali B, Scott EM, Leaper DJ. Effects of preoperative warming on the incidence of wound infection after clean surgery: a randomised controlled trial. Lancet. 2001;358(9285):876-80. https://doi.org/10.1016/S014 0-6736(01)06071-8.

5. Min L, Baoqiang C, Renhua G, Dengqun S, Peisong Z, Xudong J, et al. Randomized trial of umbilical incisional hernia in high-risk patients: extraction of gallbladder through subxiphoid port vs. umbilical port after laparoscopic cholecystectomy. Wideochir Inne Tech Maloinwazyjne. 2018;13:342-9.

6. Wang T, Hui L, Hong SJ, Wang L, You ZJ. Efficacy of intravenous lidocaine in improving post-operative nausea, vomiting and early recovery after laparoscopic gynaecological surgery. Exp Ther Med. 2019;17(6):4723-9. https://doi.org/10.3892/etm.2019.7497.

7. Indranil B, Khan James S, Phillip S, Emmanuelle D, Amal B, Sloan Erin N, et al. Effect of perioperative active body surface warming systems on analgesic and clinical outcomes: a systematic review and meta-analysis of randomized controlled trials. Anesth Analg. 2020;131:1430-43.

8. Eric N, Sophie D, Julien P, Jean-Pierre R, Michele D, Eric S, et al. Prevention of laparoscopic surgery induced hypothermia with warmed humidified insufflation: Is the experimental combination of a warming blanket synergistic? PLoS One. 2018;13:e0199369.

9. Winkler M, Akça O, Birkenberg B, Hetz H, Scheck T, Arkiliç CF, et al. Aggressive warming reduces blood loss during hip arthroplasty. Anesth Analg. 2000;91(4):978-84. https://doi.org/10.1097/00000539-20001000000039.

10. Schacham Yehoshua N, Barak C, Bajracharya Gausan R, Michael W, Nicole Z, Mao G, et al. Mild perioperative hypothermia and myocardial injury: a retrospective cohort analysis. Anesth Analg. 2018;127(6):1335-41. https://doi. org/10.1213/ANE.0000000000003840.

11. Rein EB, Filtvedt M, Walløe L, Raeder JC. Hypothermia during laparotomy can be prevented by locally applied warm water and pulsating negative pressure. Br J Anaesth. 2007:98(3):331-6. https://doi.org/10.1093/bja/ael369.

12. Andrzejowski J, Hoyle J, Eapen G, Turnbull D. Effect of prewarming on postinduction core temperature and the incidence of inadvertent perioperative hypothermia in patients undergoing general anaesthesia. Br J Anaesth. 2008;101(5):627-31. https://doi.org/10.1093/bja/aen272.

13. Lydia T, Peter M, Irene S, Maya K, Stefan M, Markus S, et al. Forced-air warming during pediatric surgery: a randomized comparison of a compressible with a noncompressible warming system. Anesth Analg. 2016;122:219-25.

14. Lenhardt R, Marker E, Goll V, Tschernich H, Kurz A, Sessler DI, et al. Mild intraoperative hypothermia prolongs postanesthetic recovery. Anesthesiology. 1997;87(6):1318-23. https://doi.org/10.1097/00000542-1 99712000-00009.

15. Torossian A. TEMMP (thermoregulation in Europe monitoring and managing patient temperature) study group. Survey on intraoperative temperature management in Europe. Eur J Anaesthesiol. 2007;24(8):668-75. https://doi.org/10.1017/S0265021507000191.

16. Sylvain B, Patey Andrea M, Baron Justine S, Karim M, Pigford Ashlee-Ann E, Bryson Gregory L, et al. Factors that influence effective perioperative temperature management by anesthesiologists: a qualitative study using the theoretical domains framework. Can J Anaesth. 2017;64:581-96.

\section{Publisher's Note}

Springer Nature remains neutral with regard to jurisdictional claims in published maps and institutional affiliations. 